\title{
Multivitamins in the Prevention of Cancer in Men: The Physicians' Health Study II Randomized Controlled Trial
}

\author{
J. Michael Gaziano, MD, Howard D. Sesso, ScD, William G. Christen, ScD, Vadim Bubes, \\ PhD, Joanne P. Smith, BA, Jean MacFadyen, BA, Miriam Schvartz, MD, JoAnn E. Manson, \\ MD, DrPH, Robert J. Glynn, ScD, and Julie E. Buring, ScD \\ Divisions of Preventive Medicine (JMG, HDS, WGC, VB, JPS, JM, MS, JEM, RJG, JEB), Aging \\ (JMG, HDS, JEB) and Cardiovascular Disease (JMG) in the Department of Medicine, Brigham \\ and Women's Hospital and Harvard Medical School; VA Boston Healthcare System, Boston, \\ Massachusetts (JMG); and the Departments of Epidemiology (HDS, JEM, JEB) and Biostatistics \\ (RJG), Harvard School of Public Health, all in Boston, MA.
}

\section{Abstract}

Address for correspondence: J. Michael Gaziano, MD, MPH, Brigham and Women's Hospital, 1620 Tremont St., Boston, MA 02120 (jmgaziano@partners.org); 617-278-0848.

Trial Registration: http://www.clinicaltrials.gov identifier: NCT00270647

Author Contributions:

Dr. Gaziano and Dr. Sesso contributed equally to this article. Drs. Gaziano, Sesso, and Glynn had full access to all of the data in the study and take responsibility for the integrity of the data and the accuracy of the data analyses. Drs. Gaziano, Sesso, Bubes, and Glynn performed and are responsible for the statistical analyses for this article.

Study concept and design: Gaziano, Sesso, Christen, Manson, Glynn, Buring.

Acquisition of data: Gaziano, Sesso, Christen, Bubes, Smith, MacFadyen, Schvartz, Manson, Glynn, Buring.

Analysis and interpretation of data: Gaziano, Sesso, Christen, Bubes, Manson, Glynn, Buring.

Drafting of the manuscript: Gaziano and Sesso.

Critical revision of the manuscript for important intellectual content: Gaziano, Sesso, Christen, Bubes, Smith, MacFadyen, Schvartz, Manson, Glynn, Buring.

Statistical analysis: Gaziano, Sesso, Bubes, Glynn.

Obtained funding: Gaziano, Sesso, Buring.

Administrative, technical, or material support: Gaziano, Sesso, Bubes, Smith, MacFadyen, Schvartz, Manson, Glynn.

Study supervision: Gaziano, Sesso, Bubes, Smith, MacFadyen, Glynn.

No other authors reported financial disclosures.

Data and Safety Monitoring Board: Voting members over the course of the PHS II trial included Lawrence Cohen, Rory Collins, Theodore Colton, I. Craig Henderson, Andrea LaCroix, Ross Prentice, and Nanette Wenger (chair); ex-officio members included Mary Francis Cotch, Jeffrey Cutler, Frederick Ferris, Jerome Fleg, Peter Greenwald, Natalie Kurinij, Howard Parnes, Marjorie Perloff, Eleanor Schron, and Alan Zonderman.

Disclaimer: Dr Gaziano, a contributing editor for JAMA, was not involved in the editorial review of or decision to publish this article.

Additional Contributions: We are deeply indebted to the 14,641 physician participants for their long-standing dedication and conscientious collaboration. We also acknowledge the long-term contributions of Charles Hennekens, MD, DrPH, Florida Atlantic University, to the Physicians' Health Study, and the exemplary contributions of the staff of the Physicians' Health Study at Brigham and Women's Hospital, under the leadership of Joanne Smith: Charlene Belanger, Eileen Bowes, Kenneth Breen, Mary Breen, Mary G. Breen, Jose Carrion, Shamikhah Curry, Colleen Evans, Ivan Fitchorov, Natalya Gomelskaya, Cindy Guo, Delia Guo, Jasmah Hanna, Beth Holman, Andrea Hrbek, Gregory Kotler, Tony Laurinaitis, Matthew Lyle, Hannah Mandel, Chandra McCarthy, Geneva McNair, Annie Murray, Leslie Power, Philomena Quinn, Harriet Samuelson, Fred Schwerin, Mickie Sheehey, Sara Tower, Martin Van Denburgh, Diana Walrond, Phyllis Johnson Wojciechowski, and Angela Zhang. Finally, we are deeply grateful for the efforts of the Physicians' Health Study Endpoints Committee, including Samuel Goldhaber, Carlos Kase, Meir Stampfer, and James Taylor, over the course of Physicians' Health Study II. Each named individual was compensated for his/her contribution as part of the grant support. 
Context-Multivitamin preparations are the most common dietary supplement, taken by at least one-third of all US adults. Limited observational studies have not provided evidence regarding associations of multivitamin use with total and site-specific cancer incidence or mortality.

Objective-To determine whether long-term multivitamin supplementation decreases the risk of total and site-specific cancer events among men.

Design-The Physicians' Health Study II is a randomized, double-blind, placebo-controlled trial of a common multivitamin that began in 1997 with treatment and follow-up through June 1, 2011.

Setting and Participants-A total of 14,641 male U.S. physicians initially aged $\geq 50$ years (mean $[ \pm \mathrm{SD}]$ age; $64.3[ \pm 9.2]$ years), including 1,312 men with a history of cancer at randomization, were enrolled.

Intervention-Daily multivitamin, as Centrum Silver.

Main Outcome Measures-A primary outcome was total cancer (excluding non-melanoma skin cancer), with prostate, colorectal, and other site-specific cancers among secondary endpoints included in this report.

Results-During a median (interquartile range) follow-up of 11.2 (10.7 to 13.3) years, there were 2,669 men with confirmed cancer, including 1,373 cases of prostate cancer and 210 cases of colorectal cancer. Compared with placebo, men taking a daily multivitamin had a statistically significant reduction in the incidence of total cancer (active and placebo multivitamin groups, 17.0 and 18.3 events, respectively, per 1,000 person-years; hazard ratio [HR], 0.92; 95\% confidence interval [CI], 0.86-0.998; $P=0.044)$. There was no significant effect of a daily multivitamin on prostate cancer (HR, $0.98 ; 95 \%$ CI, 0.88-1.09; $P=0.76$ ), colorectal cancer (HR, 0.89; 95\% CI, $0.68-1.17 ; P=0.39$ ), or other site-specific cancers There was a lower risk of cancer mortality that did not reach statistical significance (HR, $0.88 ; 95 \% \mathrm{CI}, 0.77-1.01 ; P=0.07)$. Daily multivitamin use was associated with a reduction in total cancer among 1,312 men with a baseline history of cancer (HR, 0.73; 95\% CI, 0.56-0.96; $P=0.022)$, but this did not differ significantly from that among 13,329 men initially free of cancer $(\mathrm{HR}, 0.94 ; 95 \% \mathrm{CI}, 0.87-1.02 ; P=0.15)(P$, interaction $=0.07$ ).

Conclusions-In this large prevention trial of male physicians, daily multivitamin supplementation modestly but significantly reduced the risk of total cancer.

\section{Keywords}

multivitamin; total cancer; prostate cancer; randomized clinical trial; men

\section{INTRODUCTION}

Multivitamins are the most common dietary supplement, regularly taken by at least one-third of US adults. ${ }^{1,2}$ The traditional role of a daily multivitamin is to prevent nutritional deficiency. The combination of essential vitamins and minerals contained in multivitamins may mirror healthier dietary patterns such as fruit and vegetable intake, which have been modestly and inversely associated with cancer risk in some, ${ }^{3}$ but not all, ${ }^{4,5}$ epidemiologic studies. Observational studies of long-term multivitamin use and cancer endpoints have been inconsistent. ${ }^{6-12}$ To date, large-scale randomized trials testing single or small numbers of 
higher-dose individual vitamins and minerals for cancer have generally found a lack of effect. $^{13-18}$

According to the 2010 Dietary Guidelines for Americans, "For the general, healthy population, there is no evidence to support a recommendation for the use of multivitamin/ mineral supplements in the primary prevention of chronic disease." 19 An NIH-sponsored State-of-the-Science Conference also concluded that the present evidence is insufficient to recommend either for or against the use of [multivitamins] to prevent chronic disease. ${ }^{20}$ Despite the lack of definitive trial data regarding the benefits of multivitamins in the prevention of chronic disease, including cancer, many men and women take them for precisely this reason. 21

Thus, definitive information on the potential benefits, risks, or lack thereof, related to taking a daily multivitamin may have substantial effects on personal and clinical decision-making and policy making. The Physicians' Health Study II represents the only large-scale, randomized, double-blind, placebo-controlled trial testing the long-term effects of a common multivitamin in the prevention of chronic disease. We present the findings for multivitamin use on total and other common site-specific cancers; the effects of a multivitamin on cardiovascular events, eye disease, and cognitive decline are being published separately.

\section{METHODS}

\section{Design}

The Physicians' Health Study II (PHS II) was a randomized, double-blind, placebocontrolled, $2 \times 2 \times 2 \times 2$ factorial trial evaluating the balance of risks and benefits of a multivitamin (Centrum Silver or its placebo daily; Pfizer (formerly Wyeth, American Home Products, and Lederle)), vitamin E (400 IU synthetic a-tocopherol or its placebo on alternate days; BASF Corporation), vitamin C (500 mg synthetic ascorbic acid or its placebo daily; BASF Corporation), and beta-carotene (50 mg Lurotin or placebo on alternate days; BASF Corporation) in the prevention of cancer, cardiovascular disease, eye disease, and cognitive function among 14,641 male physicians aged $\geq 50$ years. $^{22}$ The beta-carotene component was terminated on schedule in March 2003. Treatment and follow-up of the vitamin E and C components continued through August 31, 2007, their scheduled end, with findings of no overall association reported for cancer ${ }^{18}$ and cardiovascular disease. ${ }^{23}$

The study design of PHS II has been previously described in detail. ${ }^{18,22,23}$ The recruitment, enrollment, and randomization of men into PHS II occurred in two phases (Figure 1). Beginning in July 1997, in Phase 1 we invited 18,763 living participants from PHS I, a randomized trial of low-dose aspirin and beta-carotene among 22,071 male physicians, ${ }^{14,} 24$ to participate in PHS II. Men were ineligible if they reported a history of cirrhosis, active liver disease, were taking anticoagulants, or reported a serious illness that might preclude participation. Men also must have been willing to forego the use of multivitamins or individual supplements containing more than $100 \%$ of the RDA of vitamin E, vitamin C, beta-carotene, or vitamin A. Those men with a history of cancer, as well as myocardial infarction or stroke, remained eligible to enroll into PHS II. We randomized 7,641 (41\%) 
willing participants from PHS I into PHS II and retained their original PHS I beta-carotene treatment assignment.

Beginning in July 1999, in Phase 2, invitational letters and baseline questionnaires were mailed to 254,597 US male physicians aged $\geq 50$ years identified from a list provided by the American Medical Association. Through July 2001, 42,165 men responded, of whom 11,128 were willing and eligible. A 12-week placebo run-in period excluded noncompliers. ${ }^{25}$ Of 11,128 physicians who entered the run-in phase, 7,000 (63\%) willing and eligible men took at least two-thirds of their pills and were randomized into PHS II, for a total of 14,641 participants.

Men were randomized in blocks of 16, stratified by age (in 5-year age groups), prior cancer, prior cardiovascular disease, and, for the 7,641 PHS I participants, their original betacarotene treatment assignment. There were $1,312(9.0 \%)$ men with a history of cancer (excluding non-melanoma skin cancer) prior to randomization into PHS II, through either confirmed events among PHS I participants or self-reports among new PHS II participants. All participants provided written informed consent, and the Institutional Review Board at Brigham and Women's Hospital approved the PHS II research protocol.

\section{Treatment, Follow-up, and Compliance}

Participants were sent monthly calendar packs containing a multivitamin or placebo (taken daily) every six months for the first year, then annually thereafter. We also sent participants annual questionnaires asking about compliance, adverse events, new endpoints, and risk factors. A National Death Index search was performed for any participants with unknown vital status. Blinded treatment and follow-up continued through June 1, 2011, the scheduled end of the multivitamin component of PHS II, for a median (interquartile range) follow-up of 11.2 (10.7 to 13.3) years. Data analyses include validated endpoints that occurred during randomized treatment and were reported by August 2012. Morbidity and mortality followup in PHS II were extremely high, at $98.2 \%$ and $99.9 \%$, respectively. Further, morbidity and mortality follow-up as a percentage of person-time each exceeded $99.9 \%$, with only 2,991 and 79 person-years of morbidity and mortality follow-up lost out of 164,320 person-years of follow-up through June 1, 2011.

\section{Confirmation of Cancer Endpoints}

For the multivitamin component, the primary endpoints were total cancer (excluding nonmelanoma skin cancer) and major cardiovascular events. Pre-specified secondary cancer endpoints included in this report include prostate, colorectal, and other site-specific cancers. Epithelial cell cancer, total and cancer mortality, and cancer-specific death were other endpoints examined in this analysis. Epithelial cell cancer was limited to carcinomas, excluding lymphoma and leukemia. Because prostate cancer comprised over half of all confirmed cancers in PHS II most likely due to increases in screening for prostate-specific antigen (PSA) levels and detection of less aggressive cancer, we also evaluated the endpoint of total minus prostate cancer. All cancer and mortality endpoints were assessed and validated by medical record review by the PHS II Endpoints Committee composed of physicians blinded to treatment assignment; $96.9 \%$ of confirmed total cancers were based on 
pathology or cytology reports. Cases of cancer were otherwise confirmed based upon strong clinical and radiological or laboratory marker evidence. Total mortality was confirmed by the Endpoints Committee or by obtaining a death certificate. Only confirmed cancer and mortality endpoints are included in this report.

\section{Statistical Analyses}

All primary analyses classified study participants based upon the intention-to-treat principle, in which all 14,641 randomized participants were classified according to their randomized multivitamin treatment assignment and followed until the occurrence of cancer, death, loss to follow-up, or the end of the multivitamin component of PHS II on June 1, 2011, whichever came first. We used SAS version 9.2 (SAS Institute Inc.) and S-Plus (Insightful Corp.), with statistical significance set at $P<0.05$ using 2-sided tests. The PHS II was estimated to have $80 \%$ power to detect a $10 \%$ reduction of the multivitamin on the primary endpoint of total cancer based on event rates among trial participants, an average compliance of $75 \%$ during the entire treatment period, and no interaction with other randomized components.

Initial analyses displayed distributions of baseline characteristics by multivitamin treatment assignment. Consistent with previous PHS II trial analyses, ${ }^{18,} 23$ we used Cox proportional hazards models to estimate the hazard ratios (HRs) and 95\% confidence intervals (CIs) comparing event rates in the multivitamin and placebo groups. For each pre-specified endpoint, Cox models were stratified on the presence of cancer at randomization and adjusted for PHS II study design variables: age (in years), PHS cohort (original PHS I participant, new PHS II participant), and randomized vitamin E, vitamin C, and beta carotene assignments. Only first cancer events after randomization were considered for analyses of total cancer, epithelial cell cancer, and total minus prostate cancer. For analyses of total cancer, all new cancers were included, regardless of whether the participant had a baseline history of cancer. For analyses of each site-specific cancer, we excluded participants if they had a baseline history of cancer of that site. Thus, these analyses included 13,980 men initially free of prostate cancer; 14,519 initially free of colorectal cancer; and 14,610 initially free of lung cancer. Analyses of each site-specific cancer did not censor men upon occurrence of cancer at another site. Finally, for analyses of the sitespecific cancer deaths, total cancer mortality, and total mortality, we included all 14,641 participants, and for total mortality we additionally stratified on the presence of cardiovascular disease at randomization.

We tested the proportional hazards assumptions by including an interaction term for treatment with the logarithm of time, and this assumption was not violated for total cancer, prostate cancer, colorectal, or other site-specific cancers (each $P>0.05$ ). Cumulative incidence curves compared the overall effect of the multivitamin intervention on total and major site-specific cancers over time using a crude log-rank test. We then investigated whether multivitamin compliance impacted our primary results through sensitivity analyses

Additional exploratory analyses examined the effect of the multivitamin intervention on total cancer excluding the first two or five years of follow-up to explore a possible early versus late benefit associated with long-term multivitamin use. Finally, we conducted 
subgroup analyses stratified by major cancer risk factors, parental history of cancer, selected dietary factors, and other PHS II interventions. We also evaluated treatment effects within the pre-specified subgroups of 1,312 men with and 13,329 men without a baseline history of cancer. Effect modification was assessed by using interaction terms between subgroup indicators and multivitamin assignment.

\section{RESULTS}

A total of 14,641 male physicians were randomized with a mean $( \pm \mathrm{SD})$ age of $64.3( \pm 9.2)$ years. All baseline characteristics had comparable distributions between the multivitamin and placebo groups (Table 1). Participants had a mean ( \pm SD) body mass index of $26.0( \pm$ $3.6) \mathrm{kg} / \mathrm{m}^{2}$, and included a large proportion of former smokers (40.0\%) and a very low proportion of current smokers (3.6\%). Current aspirin use at baseline was high (76.3\%) in this population of physicians, in part reflective of their previous participation and results of the PHS I randomized trial testing aspirin and CVD. ${ }^{24}$ There were $1,312(9.0 \%)$ and 754 (5.1\%) men with a baseline history of cancer and CVD, respectively.

PHS II participants were followed for a mean of 11.2 years (median [interquartile range], 11.2 [10.7-13.3] years; maximum, 14.0 years), with follow-up totaling 164,320 personyears. For active multivitamin and its placebo, adherence at 4 years was $76.8 \%$ and $77.1 \%$, respectively ( $P=0.71)$; at 8 years, $72.3 \%$ and $70.7 \%(P=0.15)$; and at the end of follow-up, $67.5 \%$ and $67.1 \%(P=0.70)$. There were also no differences between the active $(81.0 \%)$ and placebo (80.3\%) groups comparing the percent of men reporting avoidance of individual non-trial multivitamin use ( $<30$ days/year) at the end of multivitamin follow-up $(P=0.35)$. During multivitamin treatment, we confirmed that 2,669 men had cancer, including 1,373 cases of prostate cancer and 210 cases of colorectal cancer, with some men experiencing multiple events. A total of 2,757 (18.8\%) men died during follow-up, including 859 (5.9\%) due to cancer.

\section{Multivitamin use and cancer}

Overall in PHS II, the rates of total cancer, which included only first cancer events during follow-up, were 17.0 and 18.3 per 1,000 person-years in the active and placebo multivitamin groups, respectively. Men taking multivitamin had a, modest reduction in total cancer incidence (HR, 0.92; 95\% CI, 0.86-0.998; $P=0.044$ ) (Table 2). The cumulative incidence curves are presented in Figure 2, (crude log-rank $P=0.05$ ).

Men taking a multivitamin had a similar modest reduction in total epithelial cell cancer (HR, $0.92 ; 95 \%$ CI, 0.85-0.997; $P=0.042)$. Approximately half of all incident cancers were prostate cancer, many of which were early stage. We found no effect of a multivitamin on prostate cancer (HR, $0.98 ; 95 \% \mathrm{CI}, 0.88-1.09 ; P=0.76$ ), whereas a multivitamin significantly reduced the risk of total cancer excluding prostate cancer (HR, $0.88 ; 95 \% \mathrm{CI}$, $0.79-0.98 ; P=0.023)$. There were statistically non-significant reductions in individual sitespecific cancers, including colorectal (HR, 0.89; 95\% CI, 0.68-1.17; $P=0.39$ ), lung (HR, $0.84 ; 95 \% \mathrm{CI}, 0.61-1.14 ; P=0.26$ ), and bladder (HR, 0.72; 95\% CI, 0.48-1.07; $P=0.10$ ), cancer, although power was limited with fewer events. There was a $12 \%$ reduction in cancer 
mortality that did not reach statistical significance (HR, $0.88 ; 95 \% \mathrm{CI}, 0.77-1.01 ; P=0.07$ ). Total mortality was not significantly reduced (HR, $0.94 ; 95 \% \mathrm{CI}, 0.88-1.02 ; P=0.13$ ).

In secondary analyses, the exclusion of the first two or five years of follow-up did not appreciably alter the results for total cancer. We also considered the effect of compliance during follow-up on our results. In analyses accounting for compliance, we did not detect any material impact on the effect of the multivitamin on risk of total cancer.

\section{Modifiers of the effect between multivitamin use and cancer}

In subgroup analyses, we examined whether selected baseline characteristics - including clinical, lifestyle, familial, and dietary factors - plus the other three randomized interventions from PHS II modified the effect of a daily multivitamin on total cancer (eTable 1). For age, the effect of a daily multivitamin on total cancer among men aged $\geq 70$ years revealed a HR of 0.82 (95\% CI, 0.72-0.93), but the test for heterogeneity across age groups with men aged 50-59 (HR, 0.96) and 60-69 years (HR, 1.01) did not reach significance $(P$, interaction $=0.06$ ). There was significant effect modification by parental history of cancer $(P$, interaction $=0.012)$; men with no parental history of cancer had a beneficial effect of a daily multivitamin on total cancer (HR, $0.86,95 \% \mathrm{CI}, 0.76-0.98 ; P=0.021$ ), while men with a parental history of cancer did not (HR, 1.05; 95\% CI, 0.94-1.17; $P=0.37)$. We otherwise found no significant heterogeneity by other clinical, lifestyle, and selected dietary factors, or by the previously terminated randomized vitamin $\mathrm{C}$, vitamin $\mathrm{E}$, and beta-carotene interventions of PHS II (all $P$, interaction $>0.05$ ).

Based upon pre-specified hypotheses, we found that daily multivitamin use was associated with was a reduction in total cancer among the 1,312 men with a baseline history of cancer (HR, $0.73 ; 95 \% \mathrm{CI}, 0.56-0.96 ; P=0.022$ ), but this result did not significantly differ from that observed among 13,329 men initially free of cancer (HR, 0.94; 95\% CI, 0.87-1.02; $P=0.15$ ) $(P$, interaction $=0.07)($ Table 3$)$. The overall rates of total cancer were 18.4 and 17.4 per 1,000 person-years in men with or without baseline cancer, respectively. Based upon the cumulative incidence curve (Figure 3), a reduction in total cancer among men with a history of cancer at baseline emerged early during multivitamin treatment and follow-up (crude logrank $P=0.018$ ). Further, the effect of a daily multivitamin on total epithelial cancer was stronger among men with a history of cancer at baseline (HR, 0.66; 95\% CI, 0.50-0.88; $P=0.004)$ than men with no history of cancer (HR, $0.95 ; 95 \% \mathrm{CI}, 0.87-1.03 ; P=0.21)(P$, interaction $=0.016$ ).

Among 1,312 men with a baseline history of cancer, we had information on the number of years since their last cancer diagnosis in 1,279 (97.5\%) men, with 620 men (76 cases of total cancer) last diagnosed $<5$ years before PHS II baseline and 659 men (138 cases of total cancer) last diagnosed $\geq 5$ years before PHS II baseline. A daily multivitamin did not have differential effects among men with more recent diagnoses $<5$ years ago (HR, 0.80; 95\% CI, $0.51-1.27 ; P=0.33$ ) versus men with more distant diagnoses $\geq 5$ years before baseline (HR, $0.70 ; 95 \%$ CI, $0.50-0.98 ; P=0.039)(P$, interaction $=0.70)$. Further, we found no effect modification by the most recent type of cancer (prostate cancer [114 men; HR, 0.66; 95\% CI, 0.34-1.27; $P=0.21]$ versus non-prostate cancer/unknown [1,165 men; HR, $0.78 ; 95 \% \mathrm{CI}$, $0.58-1.05 ; P=0.10]$ diagnosed before PHS II baseline $(P$, interaction $=0.62)$. 


\section{Adverse Effects}

In addition to the main primary and secondary endpoints, we assessed a number of potential adverse effects of daily multivitamin use, and found no significant effects on gastrointestinal tract symptoms (peptic ulcer, constipation, diarrhea, gastritis, and nausea), fatigue, drowsiness, skin discoloration, and migraine (all $P>0.05$ ). Those taking the active versus placebo multivitamin use were more likely to have skin rashes $(2,111$ and 1,973 men in corresponding active and placebo multivitamin groups; HR, 1.08; 95\% CI, 1.01-1.15; $P=0.016)$. In addition, there were inconsistent findings for daily multivitamin use on minor bleeding, with a reduction in hematuria (998 and 1,105 men in corresponding active and placebo multivitamin groups; HR, $0.89 ; 95 \% \mathrm{CI}, 0.81-0.97 ; P=0.006$ ), an increase in epistaxis (1,216 and 1,106 men in corresponding active and placebo multivitamin groups; HR, $1.11 ; 95 \%$ CI, 1.02-1.20; $P=0.016$ ), and no effect on easy bruising/other bleeding $(1,927$ and 1,902 men in corresponding active and placebo multivitamin groups; HR, 1.02; 95\% CI, 0.96-1.08; $P=0.59$ ).

\section{COMMENT}

In this large-scale, randomized, placebo-controlled trial among middle-aged and older men, long-term daily multivitamin use had a modest but statistically significant reduction in the primary endpoint of total cancer after more than a decade of treatment and follow-up. We found no evidence that this effect was driven by any individual site-specific cancers. In prespecified analyses, we found that the effect of a daily multivitamin in reducing cancer appeared stronger among men for secondary versus primary prevention of cancer in PHS II, although this difference was not significant for total cancer, but was for total epithelial cell cancer. Approximately half of those with baseline cancer in PHS II were last diagnosed $\geq 5$ years ago, and we found no suggestion that more remote versus proximate diagnoses affected cancer risk.

Total cancer rates in our trial were likely influenced by the increased surveillance for prostate-specific antigen (PSA) and subsequent diagnoses of prostate cancer during PHS II follow-up starting in the late 1990s. ${ }^{26}$ Approximately half of all confirmed cancers in PHS II were prostate cancer, of which the vast majority was earlier stage, lower grade prostate cancer with high survival rates. The significant reduction in total cancer minus prostate cancer suggests that daily multivitamin use may have a greater benefit on more clinically relevant cancer diagnoses.

In the Cancer Prevention Study II, which followed more than 1 million U.S. adults beginning in the early 1980s, multivitamin use was not associated with cancer mortality. ${ }^{27}$ The Women's Health Initiative found that multivitamins had little or no relationship with the risk of breast, colon, or other cancers in more than 160,000 women followed for an average of 8 years. ${ }^{9}$ Among 35,000 Swedish women, however, multivitamin use was associated with a $19 \%$ increased risk of breast cancer (95\% CI, 1.04-1.37) over a 10-year period compared with women not using these vitamins. ${ }^{8}$ How these results for breast and other cancers in women extend to our trial of men in PHS II remains unclear. 
Other observational studies suggest protective relationships of multivitamins with various cancers, ${ }^{28,}{ }^{29}$ no association, ${ }^{30,31}$ and possible harm. ${ }^{32}$ Studies with an association between multivitamins and specific cancers are typically of long duration, allowing for either a long latent period $^{11,12,33,34}$ or increased statistical power. For example, increasing duration of multivitamin use was strongly associated with a reduced risk of colon cancer in 88,756 Nurses' Health Study participants followed for 15 years. ${ }^{12}$ A long latency period was also noted in the Cancer Prevention Study II, with an inverse association between multivitamin use with both colon cancer incidence ${ }^{34}$ and mortality ${ }^{11}$ after more than a decade of multivitamin use; however, these findings were not supported in PHS II.

Only a few large-scale, long-term chemoprevention trials have considered combinations of selected vitamins or minerals, though not with the typical diversity of common multivitamin formulations with RDA levels of vitamins and minerals such as that tested in PHS II. The Linxian Chinese Cancer Prevention Trial, targeting 29,584 adults with low baseline nutrient status, tested a combination of beta-carotene, vitamin E, and selenium for 6 years and found significant reductions of $9 \%$ in total mortality, $13 \%$ in cancer mortality, and $21 \%$ in gastric cancer mortality. ${ }^{35}$ After 10 years of post-trial follow-up, the beneficial effects on total and cancer mortality remained. ${ }^{36}$ The Heart Protection Study tested higher doses of those three nutrients among individuals with adequate dietary intake, and found no reductions in total or site-specific cancers. ${ }^{37}$ A meta-analysis of 8 large randomized trials of folic acid/B-vitamin supplementation found no effect on total cancer. ${ }^{38}$ Finally, the Supplementation en Vitamines et Mineraux Antioxydants (SU.VI.MAX) primary prevention trial of 13,017 subjects randomized to a low-dose combination of vitamin C, vitamin E, beta-carotene, selenium, and zinc found no overall effect on total cancer, but there was a significant interaction with gender with a reduction in risk of total cancer in men only $(\mathrm{RR}=0.69 ; 95 \%$ CI, 0.53-0.91). ${ }^{39}$

While numerous individual vitamins and minerals contained in the PHS II multivitamin have postulated chemopreventive roles, it is difficult to definitively identify any single mechanism of effect through which individual or multiple components of our tested multivitamin may have reduced cancer risk. The reduction in total cancer risk in PHS II argues that the broader combination of low-dose vitamins and minerals contained in the PHS II multivitamin (eTable 2), rather than an emphasis on previously tested high-dose vitamins and mineral trials, may be paramount for cancer prevention. The role of a food-focused cancer prevention strategy such as targeted fruit and vegetable intake remains promising 40 but unproven given the inconsistent epidemiologic evidence ${ }^{41}$ and lack of definitive trial data.

One explanation for results of some previous trials of supplements has been that the trial populations are already well-nourished. ${ }^{42}$ This may also be particularly true in PHS II, comprised of male physicians, although population-based clinical trials also recruit healthier individuals. ${ }^{43-45}$ PHS II participants represent, on average, a well-nourished population for whom the effect of a daily multivitamin on cancer outcomes may be less applicable to those of poorer nutritional status. Additional studies need to evaluate how the range of baseline nutritional status modifies the effect of a daily multivitamin on cancer. 
Strengths of PHS II include the long duration of treatment and follow-and consistently good adherence to taking a daily multivitamin. The inclusion of physician participants provided high-quality reporting of health information. We are unaware of other long-term clinical trials testing a common multivitamin in the prevention of cancer and chronic disease. We selected a commonly used multivitamin formulation, Centrum Silver, at the time we initiated PHS II in 1997 to increase the potential generalizability of our findings.

Several limitations should also be considered. The formulations of the multivitamin preparation used in our trial and other multivitamin preparations have changed over time, reflecting evolving perspectives and priorities in nutrition. For example, since PHS II was initiated, in the commercial form of this multivitamin, vitamin D increased from 400 to 500 IU, vitamin A (\% as beta-carotene) decreased from 5000 IU (50\%) to $2500 \mathrm{IU}(40 \%)$, and $250 \mu \mathrm{g}$ lutein and $300 \mu \mathrm{g}$ lycopene were added. However, the formulation of the multivitamin used throughout PHS II (eTable 2) remained the same, resulting in a consistent intervention in our trial. An improved understanding of the effects of single versus combined nutrients - at usual levels of dietary intake - on intermediate mechanisms leading to cancer is critically needed.

It is unclear how easily our trial results for cancer outcomes may be replicated given the high prevalence of multivitamin use in adults, and difficulty of conducting a long-term, blinded clinical trial. This is especially important given the potential challenge of generalizing to younger men and women and racial and ethnic groups not included in PHS II. It remains possible that more effective chemoprevention via multivitamins may occur with longer treatment or follow-up than conducted to date in PHS II, given the apparent latent results on colon cancer and mortality in some cohorts. ${ }^{11,12,34}$ This is particularly salient in our analyses of site-specific cancers, for which continued PHS II follow-up would increase statistical power and detect any emergent latent effects. Compliance remains of concern as in any long-term trial, but compliance with the multivitamin component of PHS II remained consistently good during a mean follow-up of 11 years. Drop-in rates of outside multivitamin use did increase during follow-up, paralleling general population trends of increased vitamin supplement use in the US, 2,46 but there were no differences in rates in active versus placebo multivitamin groups and analyses accounting for compliance did not greatly affect HRs of total and site-specific cancers.

As in any trial, the role of chance must be considered. This is particularly important when multiple hypotheses are being addressed. In PHS II, we had only two primary outcomes total cancer and major cardiovascular events. However, there are additional secondary outcomes that include eye disease, cognitive function, and a number of pre-specified secondary analyses. Caution must be applied in the interpretation of these analyses..

In this large-scale randomized trial of 14,641 middle-aged and older men, a daily multivitamin supplement significantly but modestly reduced the risk of total cancer during a mean of 11 years of treatment and follow-up. These data provide support for the potential use of multivitamin supplements in the prevention of cancer in middle-aged and older men. 


\section{Supplementary Material}

Refer to Web version on PubMed Central for supplementary material.

\section{Acknowledgments}

Funding/Support: Supported by grants CA 097193, CA 34944, CA 40360, HL 26490, and HL 34595 from the National Institutes of Health (Bethesda, MD), and an investigator-initiated grant from BASF Corporation (Florham Park, NJ). Study agents and packaging were provided by BASF Corporation and Pfizer (formerly Wyeth, American Home Products, and Lederle) (New York, NY), and study packaging was provided by DSM Nutritional Products, Inc. (formerly Roche Vitamins) (Parsippany, NJ).

Role of the Sponsors: NIH, BASF, Pfizer, and DSM Nutritional Products, Inc had no role in the study design; conduct of the study; collection, management, analysis, and interpretation of the data; or preparation, review, or approval of the manuscript.

\section{Relevant Financial Disclosures:}

Dr. Gaziano reported receiving investigator-initiated research funding from the National Institutes of Health the Veterans Administration, and the BASF Corporation, assistance with study agents and packaging from BASF Corporation and Pfizer (formerly Wyeth, American Home Products, and Lederle), and assistance with study packaging provided by DSM Nutritional Products, Inc. (formerly Roche Vitamins).

Dr. Sesso reported receiving investigator-initiated research funding from the National Institutes of Health, the Tomato Products Wellness Council, and Cambridge Theranostics, Ltd.

Dr. Christen reported receiving research funding support from the National Institutes of Health, Harvard University (Clinical Nutrition Research Center), and DSM Nutritional Products Inc. (formerly Roche Vitamins).

Dr. Manson reported receiving investigator-initiated research funding from the National Institutes of Health, and assistance with study pills and packaging from BASF and Cognis Corporations for the Women's Antioxidant and Folic Acid Cardiovascular Study and from Pronova BioPharma and Pharmavite for the VIT amin D and OmegA-3 Tria $L$, and funding from the non-profit Aurora Foundation.

Dr. Glynn reported receiving investigator-initiated research funding from the National Institutes of Health, BristolMeyers Squibb, AstraZeneca, and Novartis, and signed a consulting agreement with Merck to give an invited talk.

Dr. Buring reported receiving investigator-initiated research funding from the National Institutes of Health, and assistance with study pills and packaging from Natural Source Vitamin E Association and Bayer Healthcare for the Women's Health Study.

\section{References}

1. Bailey RL, Gahche JJ, Lentino CV, et al. Dietary supplement use in the United States 2003-2006. J Nutr. 2011; 141(2):261-266. [PubMed: 21178089]

2. Gahche J, Bailey R, Burt V, et al. Dietary supplement use among U.S. adults has increased since NHANES III (1988-1994). NCHS Data Brief. 2011; (61):1-8. [PubMed: 21592424]

3. Boffetta P, Couto E, Wichmann J, et al. Fruit and vegetable intake and overall cancer risk in the European Prospective Investigation into Cancer and Nutrition (EPIC). J Natl Cancer Inst. 2010; 102(8):529-537. [PubMed: 20371762]

4. Lof M, Sandin S, Lagiou P, Trichopoulos D, Adami HO, Weiderpass E. Fruit and vegetable intake and risk of cancer in the Swedish women's lifestyle and health cohort. Cancer Causes Control. 2011; 22(2):283-289. [PubMed: 21125418]

5. Hung HC, Joshipura KJ, Jiang R, et al. Fruit and vegetable intake and risk of major chronic disease. J Natl Cancer Inst. 2004; 96(21):1577-1584. [PubMed: 15523086]

6. Li K, Kaaks R, Linseisen J, Rohrmann S. Vitamin/mineral supplementation and cancer, cardiovascular, and all-cause mortality in a German prospective cohort (EPIC-Heidelberg). Eur $\mathbf{J}$ Nutr. 2012; 51(4):407-413. [PubMed: 21779961] 
7. Park SY, Murphy SP, Wilkens LR, Henderson BE, Kolonel LN. Multivitamin use and the risk of mortality and cancer incidence: the multiethnic cohort study. Am J Epidemiol. 2011; 173(8):906914. [PubMed: 21343248]

8. Larsson SC, Akesson A, Bergkvist L, Wolk A. Multivitamin use and breast cancer incidence in a prospective cohort of Swedish women. Am J Clin Nutr. 2011; 91(5):1268-1272. [PubMed: 20335555]

9. Neuhouser ML, Wassertheil-Smoller S, Thomson C, et al. Multivitamin use and risk of cancer and cardiovascular disease in the Women's Health Initiative cohorts. Arch Intern Med. 2009; 169(3): 294-304. [PubMed: 19204221]

10. Stevens VL, McCullough ML, Diver WR, et al. Use of multivitamins and prostate cancer mortality in a large cohort of US men. Cancer Causes Control. 2005; 16(6):643-650. [PubMed: 16049802]

11. Jacobs EJ, Connell CJ, Patel AV, et al. Multivitamin use and colon cancer mortality in the Cancer Prevention Study II cohort (United States). Cancer Causes Control. 2001; 12(10):927-934. [PubMed: 11808712]

12. Giovannucci E, Stampfer MJ, Colditz GA, et al. Multivitamin use, folate, and colon cancer in women in the Nurses' Health Study. Ann Intern Med. 1998; 129(7):517-524. [PubMed: 9758570]

13. The effect of vitamin $E$ and beta carotene on the incidence of lung cancer and other cancers in male smokers. The Alpha-Tocopherol, Beta Carotene Cancer Prevention Study Group. N Engl J Med. 1994; 330(15):1029-1035. [PubMed: 8127329]

14. Hennekens CH, Buring JE, Manson JE, et al. Lack of effect of long-term supplementation with beta carotene on the incidence of malignant neoplasms and cardiovascular disease. N Engl J Med. 1996; 334(18):1145-1149. [PubMed: 8602179]

15. Lee IM, Cook NR, Gaziano JM, et al. Vitamin E in the primary prevention of cardiovascular disease and cancer: the Women's Health Study: a randomized controlled trial. JAMA. 2005; 294(1):56-65. [PubMed: 15998891]

16. Lonn E, Bosch J, Yusuf S, et al. Effects of long-term vitamin E supplementation on cardiovascular events and cancer: a randomized controlled trial. JAMA. 2005; 293(11):1338-1347. [PubMed: 15769967]

17. Lin J, Cook NR, Albert C, et al. Vitamins C and E and beta carotene supplementation and cancer risk: a randomized controlled trial. J Natl Cancer Inst. 2009; 101(1):14-23. [PubMed: 19116389]

18. Gaziano JM, Glynn RJ, Christen WG, et al. Vitamins E and C in the prevention of prostate and total cancer in men: the Physicians' Health Study II randomized controlled trial. JAMA. 2009; 301(1):52-62. [PubMed: 19066368]

19. [Accessed on Nov. 18, 2010] US Department of Agriculture and US Department of Health and Human Services. Report of the Dietary Guidelines Advisory Committee on the Dietary Guidelines for Americans, 2010. 2010 Jun 15. Available at: http://www.cnpp.usda.gov/DGAs2010DGACReport.htm

20. National Institutes of Health State-of-the-science conference statement: multivitamin/mineral supplements and chronic disease prevention. Ann Intern Med. 2006; 145(5):364-371. [PubMed: 16880454]

21. Ervin, RB.; Wright, JD.; Kennedy-Stephenson, J. Vital Health Stat. Vol. 11. Washington DC: National Center for Health Statistics; 1999. Use of dietary supplements in the United States, 198894; p. i-14.

22. Christen WG, Gaziano JM, Hennekens CH. Design of Physicians' Health Study II--a randomized trial of beta- carotene, vitamins $\mathrm{E}$ and $\mathrm{C}$, multivitamins, in prevention of cancer, cardiovascular disease, and eye disease, and review of results of completed trials. Ann Epidemiol. 2000; 10(2): 125-134. [PubMed: 10691066]

23. Sesso HD, Buring JE, Christen WG, et al. Vitamins E and C in the prevention of cardiovascular disease in men: the Physicians' Health Study II randomized controlled trial. JAMA. 2008; 300(18): 2123-2133. [PubMed: 18997197]

24. Final report on the aspirin component of the ongoing Physicians' Health Study. Steering Committee of the Physicians' Health Study Research Group. N Engl J Med. 1989; 321(3):129135. [PubMed: 2664509] 
25. Lang JM, Buring JE, Rosner B, Cook N, Hennekens CH. Estimating the effect of the run-in on the power of the Physicians' Health Study. Stat Med. 1991; 10(10):1585-1593. [PubMed: 1947514]

26. Neppl-Huber C, Zappa M, Coebergh JW, et al. Changes in incidence, survival and mortality of prostate cancer in Europe and the United States in the PSA era: additional diagnoses and avoided deaths. Ann Oncol. 2012; 23(5):1325-1334. [PubMed: 21965474]

27. Watkins ML, Erickson JD, Thun MJ, Mulinare J, Heath CW Jr. Multivitamin use and mortality in a large prospective study. Am J Epidemiol. 2000; 152(2):149-162. [PubMed: 10909952]

28. Asgari MM, Chren MM, Warton EM, Friedman GD, White E. Supplement use and risk of cutaneous squamous cell carcinoma. J Am Acad Dermatol. 2011

29. Kwan ML, Greenlee H, Lee VS, et al. Multivitamin use and breast cancer outcomes in women with early-stage breast cancer: the Life After Cancer Epidemiology study. Breast Cancer Res Treat. 2011; 130(1):195-205. [PubMed: 21559824]

30. Chan AL, Leung HW, Wang SF. Multivitamin supplement use and risk of breast cancer: a metaanalysis. Ann Pharmacother. 2011; 45(4):476-484. [PubMed: 21487086]

31. Pocobelli G, Peters U, Kristal AR, White E. Use of supplements of multivitamins, vitamin C, vitamin E in relation to mortality. Am J Epidemiol. 2009; 170(4):472-483. [PubMed: 19596711]

32. Zhang Y, Coogan P, Palmer JR, Strom BL, Rosenberg L. Vitamin and mineral use and risk of prostate cancer: the case-control surveillance study. Cancer Causes Control. 2009; 20(5):691-698. [PubMed: 19093214]

33. White E, Shannon JS, Patterson RE. Relationship between vitamin and calcium supplement use and colon cancer. Cancer Epidemiol Biomarkers Prev. 1997; 6(10):769-774. [PubMed: 9332757]

34. Jacobs EJ, Connell CJ, Chao A, et al. Multivitamin use and colorectal cancer incidence in a US cohort: does timing matter? Am J Epidemiol. 2003; 158(7):621-628. [PubMed: 14507597]

35. Blot WJ, Li JY, Taylor PR, et al. Nutrition intervention trials in Linxian, China: supplementation with specific vitamin/mineral combinations, cancer incidence, and disease- specific mortality in the general population. J Natl Cancer Inst. 1993; 85(18):1483-1492. [PubMed: 8360931]

36. Qiao YL, Dawsey SM, Kamangar F, et al. Total and cancer mortality after supplementation with vitamins and minerals: follow-up of the Linxian General Population Nutrition Intervention Trial. J Natl Cancer Inst. 2009; 101(7):507-518. [PubMed: 19318634]

37. MRC/BHF Heart Protection Study of antioxidant vitamin supplementation in 20,536 high-risk individuals: a randomised placebo-controlled trial. Lancet. 2002; 360(9326):23-33. [PubMed: 12114037]

38. Clarke R, Halsey J, Lewington S, et al. Effects of lowering homocysteine levels with B vitamins on cardiovascular disease, cancer, and cause-specific mortality: Meta-analysis of 8 randomized trials involving 37485 individuals. Arch Intern Med. 2010; 170(18):1622-1631. [PubMed: 20937919]

39. Hercberg S, Galan P, Preziosi P, et al. The SU.VI.MAX Study: a randomized, placebo-controlled trial of the health effects of antioxidant vitamins and minerals. Arch Intern Med. 2004; 164(21): 2335-2342. [PubMed: 15557412]

40. Boeing H, Bechthold A, Bub A, et al. Critical review: vegetables and fruit in the prevention of chronic diseases. Eur J Nutr. 2012; 51(6):637-663. [PubMed: 22684631]

41. Riboli E, Norat T. Epidemiologic evidence of the protective effect of fruit and vegetables on cancer risk. Am J Clin Nutr. 2003; 78(3 Suppl):559S-569S. [PubMed: 12936950]

42. Morris MC, Tangney CC. A potential design flaw of randomized trials of vitamin supplements. JAMA. 2011; 305(13):1348-1349. [PubMed: 21467288]

43. Sesso HD, Gaziano JM, VanDenburgh M, Hennekens CH, Glynn RJ, Buring JE. Comparison of baseline characteristics and mortality experience of participants and nonparticipants in a randomized clinical trial. the Physicians' Health Study. Control Clin Trials. 2002; 23(6):686-702. [PubMed: 12505246]

44. Block G, Jensen CD, Norkus EP, et al. Usage patterns, health, and nutritional status of long-term multiple dietary supplement users: a cross-sectional study. Nutrition Journal. 2007; 6(1):30. [PubMed: 17958896]

45. Sebastian RS, Cleveland LE, Goldman JD, Moshfegh AJ. Older adults who use vitamin/mineral supplements differ from nonusers in nutrient intake adequacy and dietary attitudes. J Am Diet Assoc. 2007; 107(8):1322-1332. [PubMed: 17659898] 
46. Park K, Harnack L, Jacobs DR Jr. Trends in dietary supplement use in a cohort of postmenopausal women from Iowa. Am J Epidemiol. 2009; 169(7):887-892. [PubMed: 19208725] 


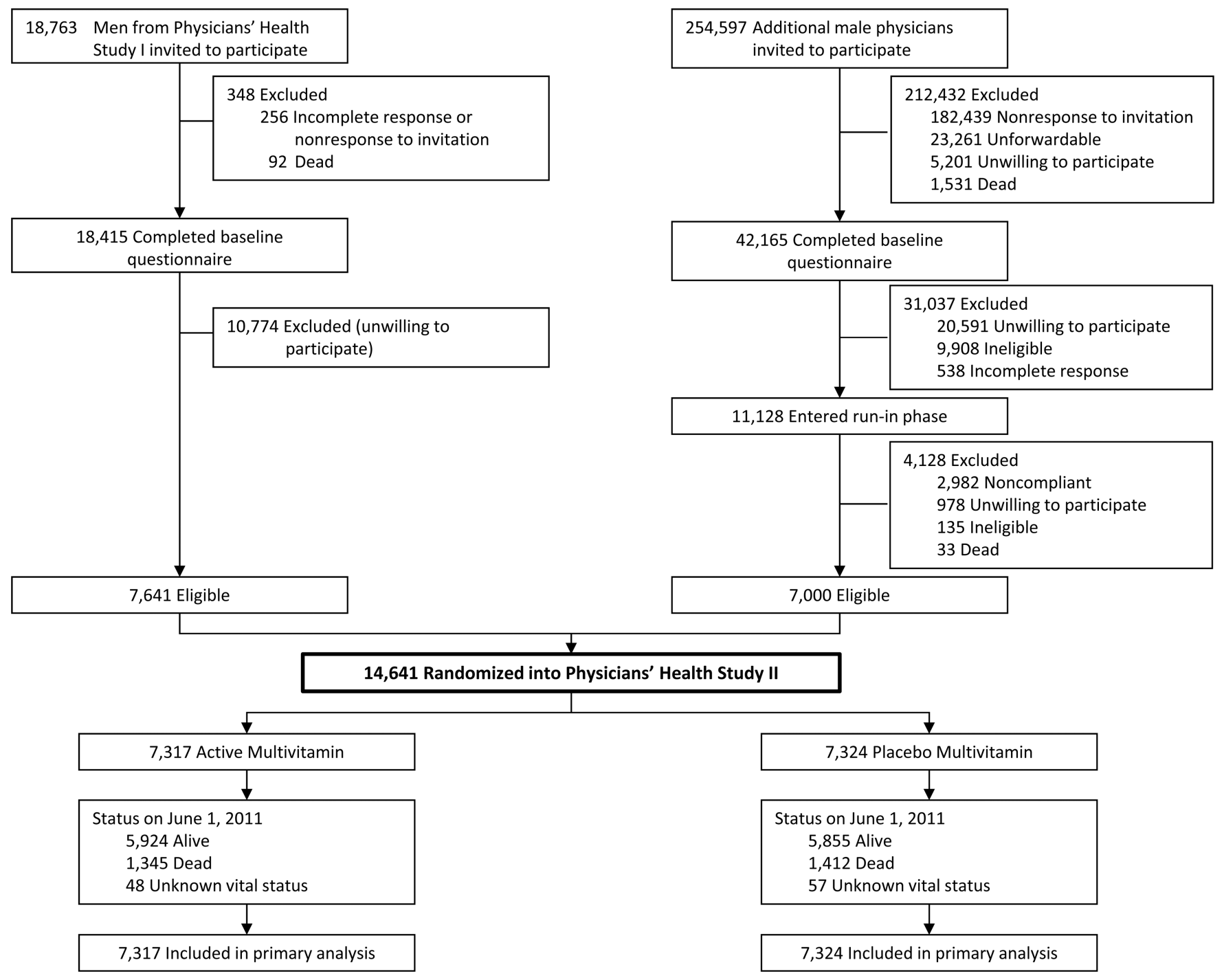

Figure 1.

Flow diagram of participants from screening to completion of the multivitamin component of the Physicians' Health Study (PHS) II.*

* Those classified as "unforwardable" were not able to be contacted by mail. 


\section{Total Cancer}

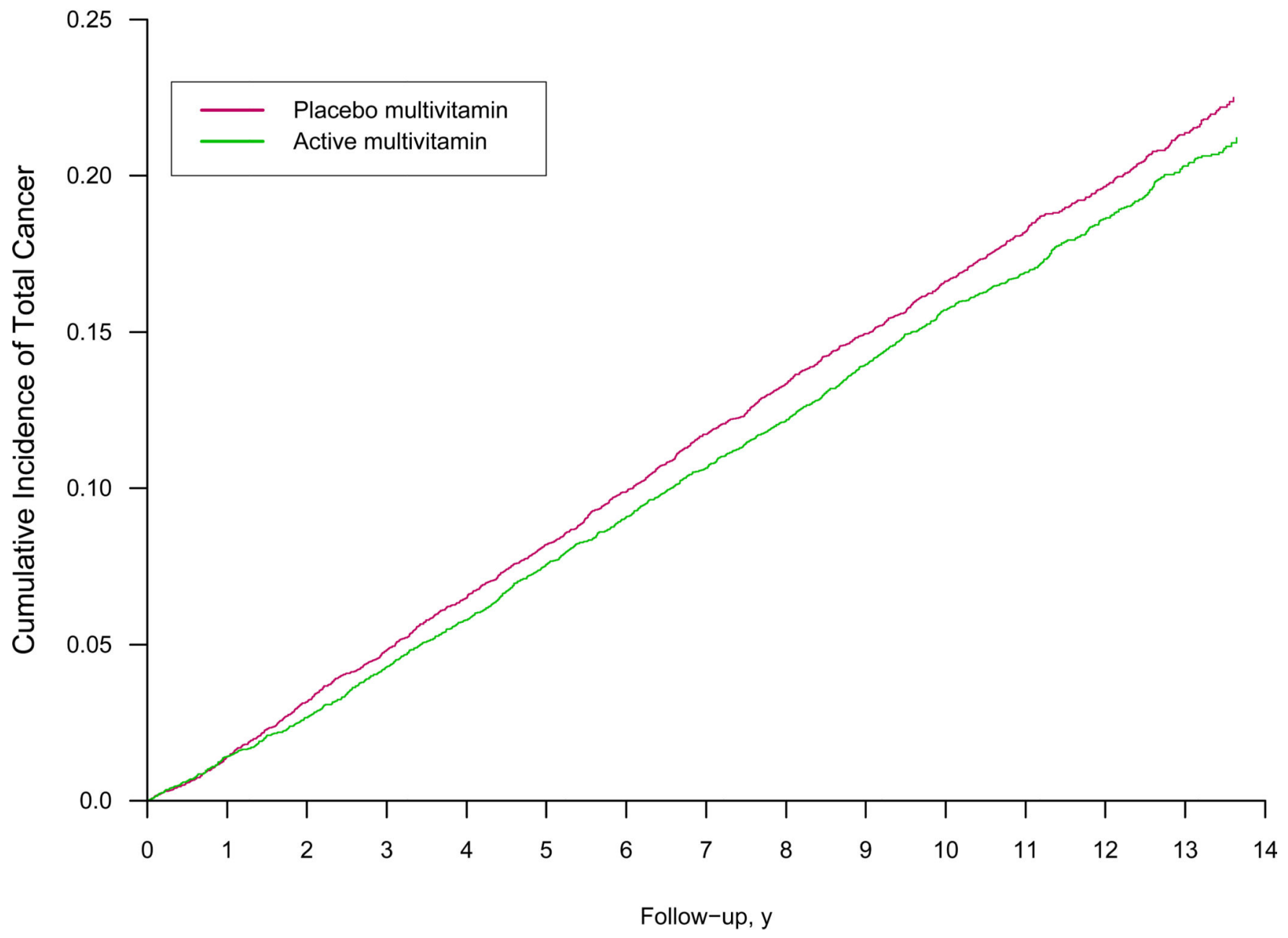

Number at Risk

\begin{tabular}{|c|c|c|c|c|c|c|c|c|c|c|c|c|c|}
\hline Plac & 7324 & 7179 & 7006 & 6825 & 6645 & 6443 & 6260 & 6049 & 5858 & 5660 & 5441 & 3533 & 2439 \\
\hline Active & 7317 & 7168 & 7023 & 6857 & 6689 & 6481 & 6321 & 6116 & 5929 & 5725 & 5514 & 3597 & 2482 \\
\hline
\end{tabular}




\section{Colorectal Cancer}

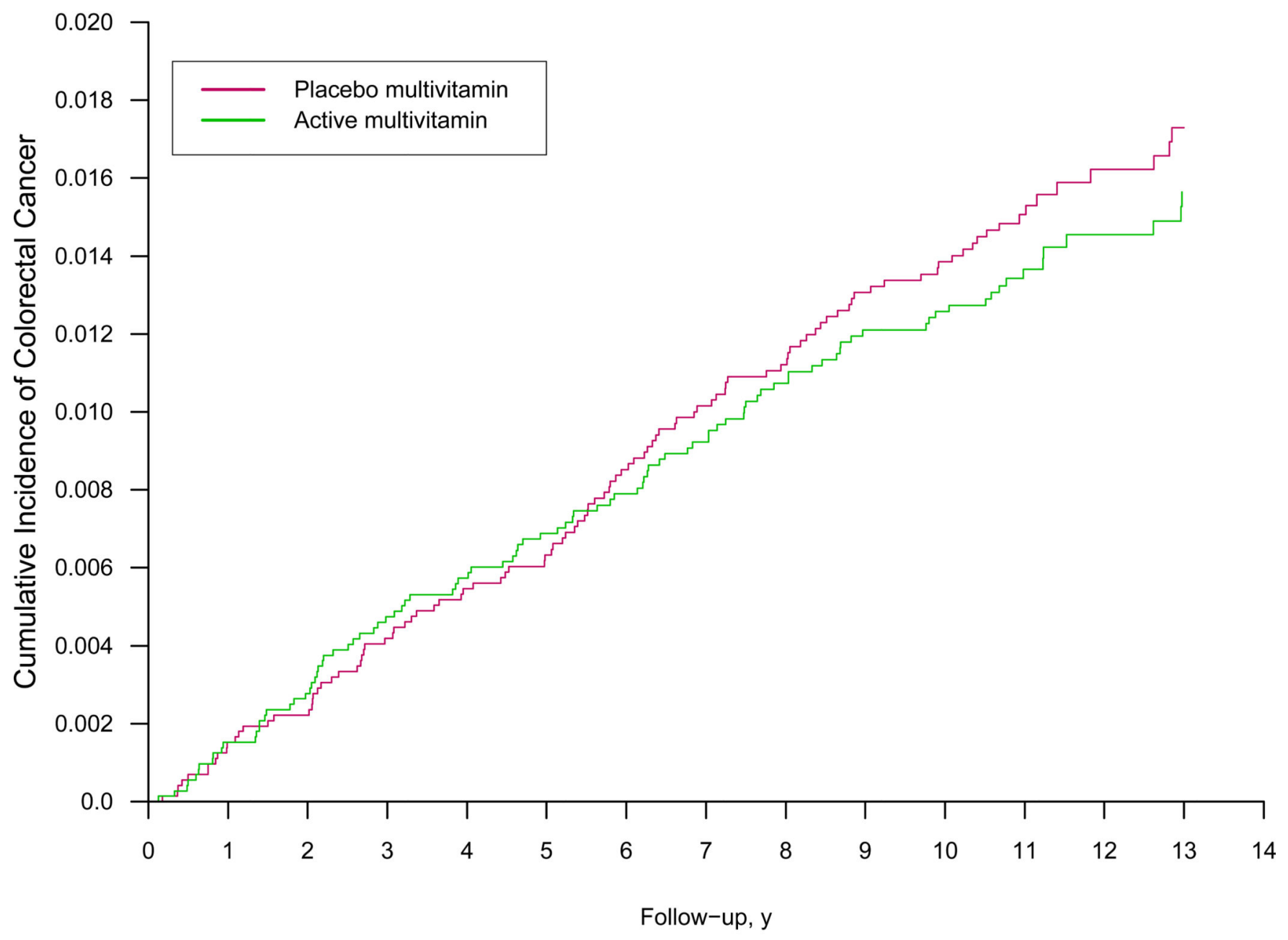

Number at Risk

\begin{tabular}{|c|c|c|c|c|c|c|c|c|c|c|c|c|c|}
\hline & 7264 & 7203 & 7137 & 7039 & 6947 & 6840 & 6726 & 6601 & 6469 & \multirow{2}{*}{$\begin{array}{l}6325 \\
6388\end{array}$} & \multirow{2}{*}{$\begin{array}{l}6178 \\
6252\end{array}$} & \multirow{2}{*}{$\begin{array}{l}4136 \\
4188\end{array}$} & \multirow{2}{*}{$\begin{array}{l}2916 \\
2938\end{array}$} \\
\hline Active & 7255 & 7197 & 7128 & 7052 & 6973 & 6862 & 6777 & 6643 & 6519 & & & & \\
\hline
\end{tabular}




\section{Prostate Cancer}

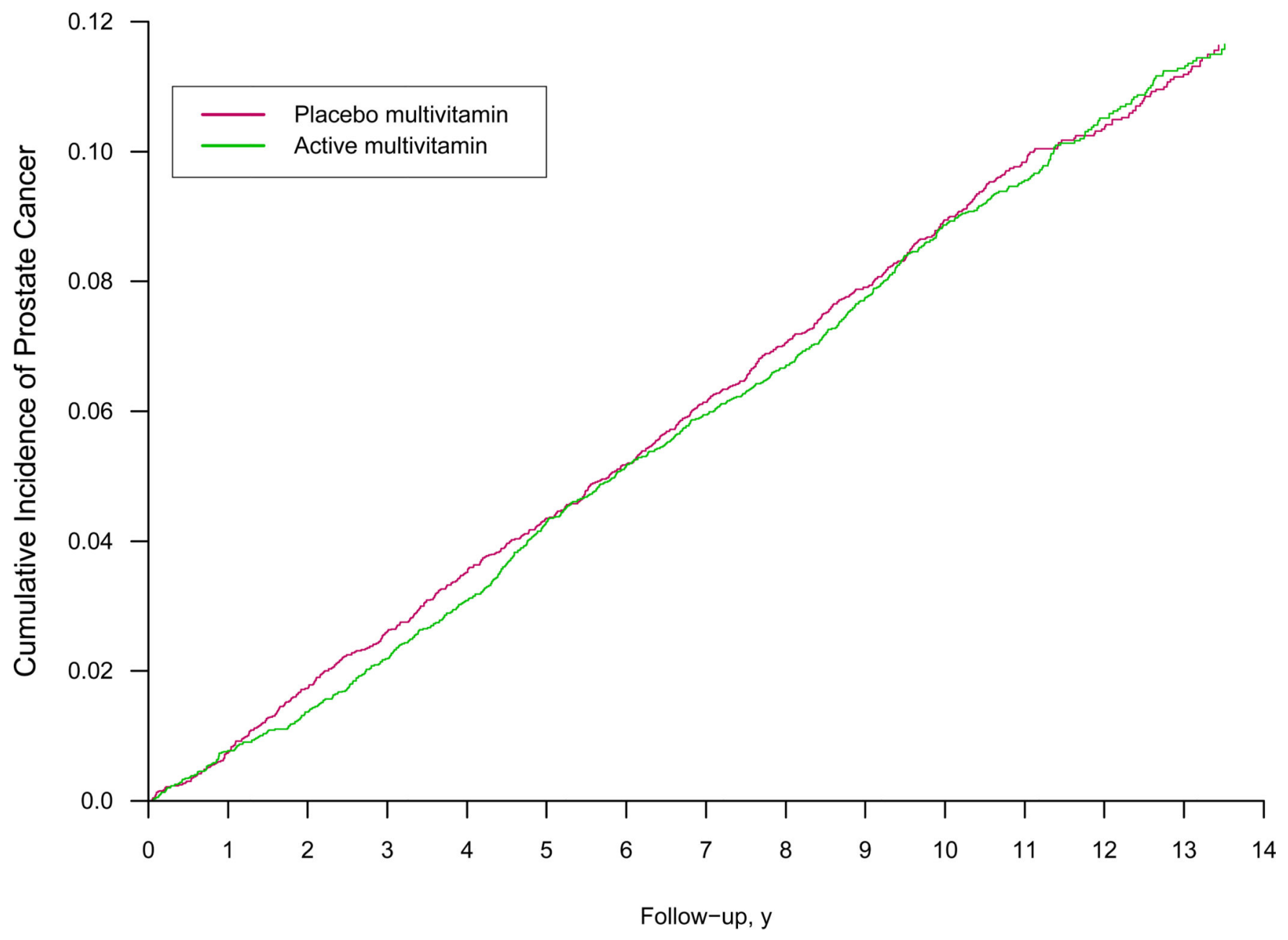

Number at Risk

$\begin{array}{rllllllllllllll}\text { Placebo } & 6992 & 6895 & 6774 & 6641 & 6505 & 6358 & 6220 & 6054 & 5886 & 5728 & 5540 & 3652 & 2537 & 2240 \\ \text { Active } & 6988 & 6886 & 6791 & 6678 & 6546 & 6374 & 6252 & 6095 & 5951 & 5772 & 5583 & 3688 & 2529 & 2240\end{array}$




\section{Lung Cancer}

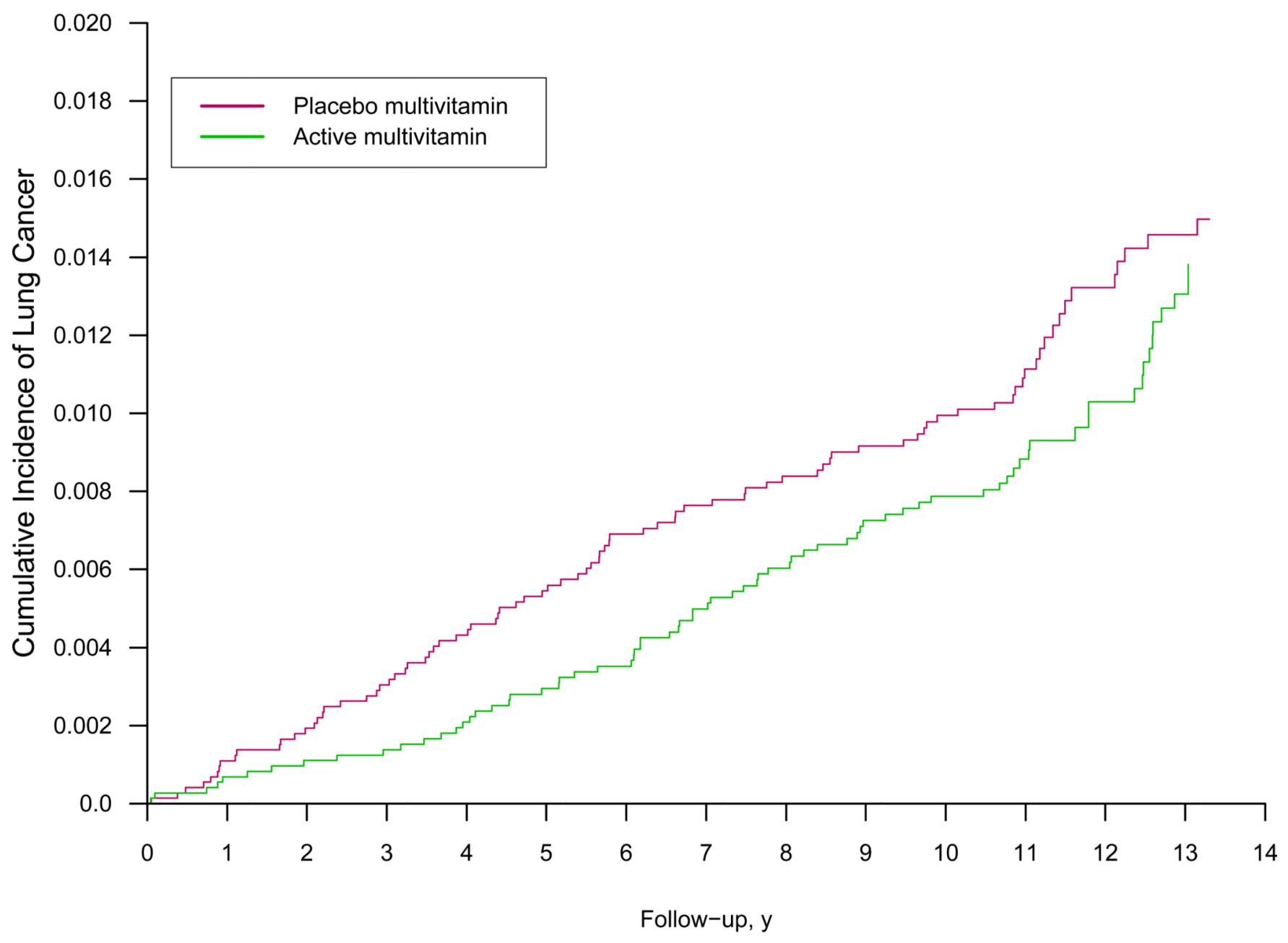

\begin{tabular}{|c|c|c|c|c|c|c|c|c|c|c|c|c|c|c|}
\hline \multirow[b]{2}{*}{ Placebo } & \multirow[b]{2}{*}{7310} & \multicolumn{13}{|c|}{ Number at Risk } \\
\hline & & 7256 & 7196 & 7103 & 7018 & 6907 & 6798 & 6679 & 6542 & 6404 & 6248 & 4189 & 2956 & 2626 \\
\hline Active & 7300 & 7248 & 7183 & 7119 & 7034 & 6926 & 6844 & 6710 & 6588 & 6455 & 6316 & 4238 & 2978 & 2641 \\
\hline
\end{tabular}

Figure 2.

Cumulative incidence rates of (part A) total cancer, (part B) prostate cancer, and (part C) colorectal cancer by randomized multivitamin assignment in the Physicians' Health Study II.

* The reduction in the number at risk from 10 to 11 years reflects the two phases of PHS II recruitment; PHS I physicians initially enrolled in Phase 1 starting in 1997 were followed longer on average (mean of 13 years) than new physicians recruited in Phase 2 starting in 1999 (mean of 10 years). Crude log-rank $P=0.05$ for total cancer, $P=0.78$ for prostate cancer, $P=0.38$ for colorectal cancer, and $P=0.26$ for lung cancer. 


\section{Primary Prevention}

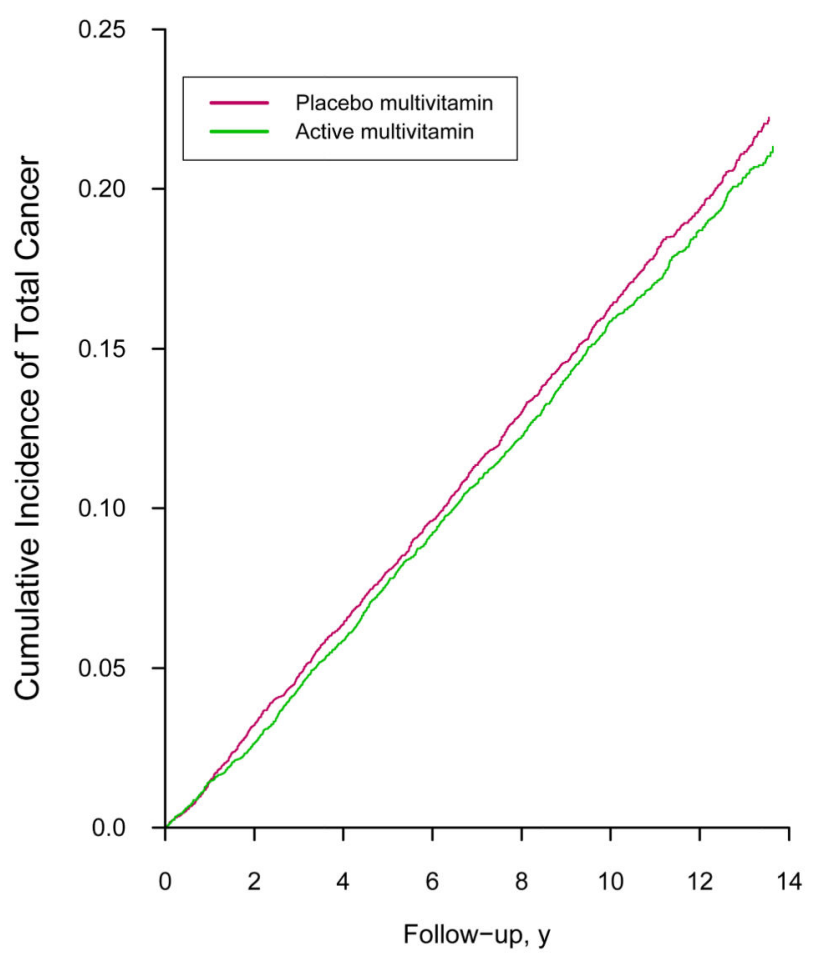

Number at Risk

$\begin{array}{llllllll}\text { Placebo } & 6660 & 6385 & 6094 & 5775 & 5433 & 5065 & 2283\end{array}$

$\begin{array}{llllllll}\text { Active } & 6669 & 6425 & 6130 & 5811 & 5475 & 5103 & 2302\end{array}$
Secondary Prevention

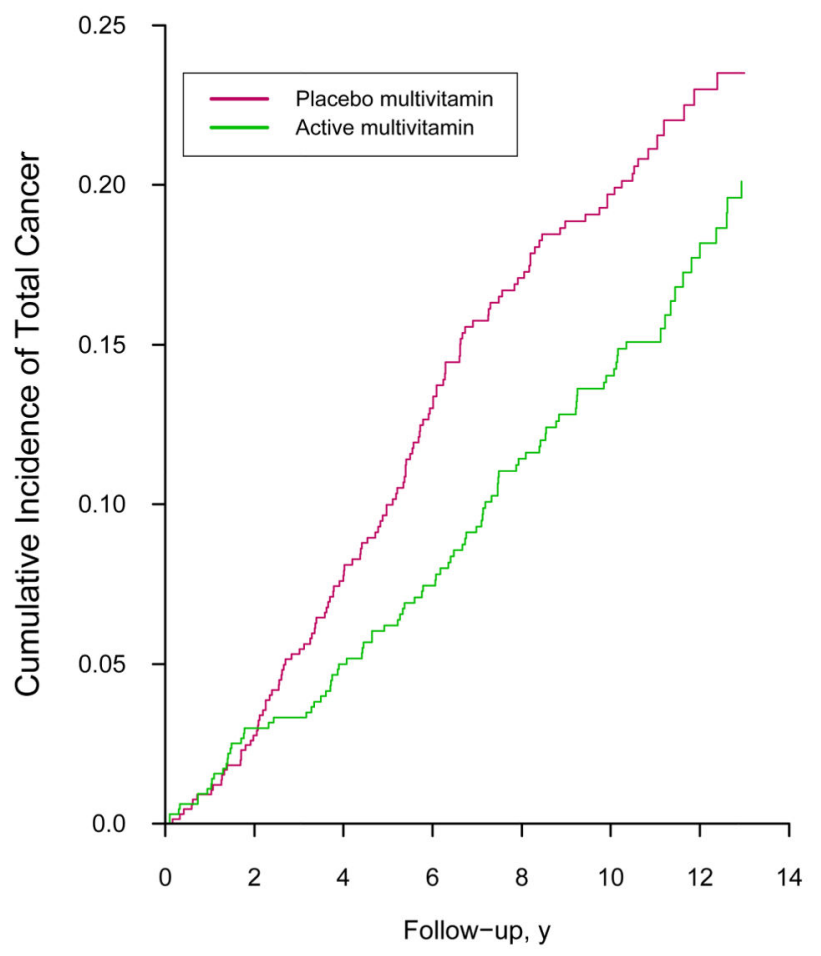

Number at Risk

$\begin{array}{cccccccc}\text { Placebo } & 664 & 621 & 551 & 485 & 425 & 376 & 156 \\ \text { Active } & 648 & 598 & 559 & 510 & 454 & 411 & 180\end{array}$

Figure 3.

Hazard ratios (HRs) and 95\% confidence intervals (CIs) of total cancer among 13,329 men with no baseline history of cancer (part A; Primary Prevention) and 1,312 men with a baseline history of cancer (part B; Secondary Prevention) in the Physicians' Health Study II. * Crude log-rank $P=0.018$ for 13,329 men with no baseline history of cancer, and crude logrank $P=0.19$ for 1,312 men with a baseline history of cancer. 


\section{Table 1}

Baseline characteristics according to multivitamin treatment assignment in 14,641 men from the Physicians' Health Study (PHS) II.

\begin{tabular}{|c|c|c|}
\hline & \multicolumn{2}{|c|}{ Men, No. $(\%)^{a}$} \\
\hline & \multicolumn{2}{|c|}{ Multivitamin $^{b}$} \\
\hline Self-reported baseline characteristics & $\underset{(n=7,317)}{\text { Active }}$ & $\begin{array}{c}\text { Placebo } \\
(\mathbf{n}=7,324)\end{array}$ \\
\hline Age $($ mean \pm SD, years $)$ & $64.2 \pm 9.1$ & $64.3 \pm 9.2$ \\
\hline \multicolumn{3}{|l|}{ Age (No. (\%)) } \\
\hline 50-59 years & $2,944(40.2)$ & $2,947(40.2)$ \\
\hline $60-69$ years & $2,348(32.1)$ & $2,348(32.1)$ \\
\hline$>0$ years & $2,025(27.7)$ & $2,029(27.7)$ \\
\hline Body mass index $\left(\right.$ mean $\left.\pm \mathrm{SD}, \mathrm{kg} / \mathrm{m}^{2}\right)$ & $26.0 \pm 3.6$ & $26.0 \pm 3.7$ \\
\hline \multicolumn{3}{|l|}{ Cigarette smoking (No. (\%)) } \\
\hline Never & $4,145(56.7)$ & $4,107(56.1)$ \\
\hline Former & $2,908(39.8)$ & $2,944(40.2)$ \\
\hline Current & $255(3.5)$ & $269(3.7)$ \\
\hline \multicolumn{3}{|l|}{ Exercise $\gg 1$ time/wk (No. (\%)) } \\
\hline No & 2,699 (37.8) & $2,806(39.3)$ \\
\hline Yes & $4,444(62.2)$ & $4,328(60.7)$ \\
\hline \multicolumn{3}{|l|}{ Alcohol consumption (No. (\%)) } \\
\hline Rarely/never & $1,391(19.2)$ & $1,339(18.4)$ \\
\hline$\geq 1$ drink/month & $5,874(80.9)$ & $5,942(81.6)$ \\
\hline \multicolumn{3}{|l|}{ Current aspirin use (No. (\%)) } \\
\hline No & $1,625(22.7)$ & $1,636(22.7)$ \\
\hline Yes & $5,602(77.5)$ & $5,565(77.3)$ \\
\hline \multicolumn{3}{|l|}{ Parental history of cancer $(\text { No. }(\%))^{c}$} \\
\hline No & $2,956(47.1)$ & $2,881(45.9)$ \\
\hline Yes & $3,319(52.9)$ & $3,402(52.9)$ \\
\hline \multicolumn{3}{|l|}{ Parental history of prostate cancer $(\text { No. }(\%))^{c}$} \\
\hline No & $5,759(89.4)$ & $5,746(90.0)$ \\
\hline Yes & $682(10.6)$ & $642(10.1)$ \\
\hline \multicolumn{3}{|l|}{ Parental history of colorectal cancer $(\text { No. }(\%))^{c}$} \\
\hline No & $5,559(88.7)$ & $5,485(87.8)$ \\
\hline Yes & $708(11.3)$ & $759(12.2)$ \\
\hline \multicolumn{3}{|l|}{ Self-reported history of cancer (No. (\%)) } \\
\hline No & $6,669(91.1)$ & $6,660(90.9)$ \\
\hline Yes & $648(8.9)$ & $664(9.1)$ \\
\hline Self-reported history of prostate cancer (No. (\%)) & & \\
\hline
\end{tabular}




\begin{tabular}{|c|c|c|}
\hline & \multicolumn{2}{|c|}{ Men, No. $(\%)^{a}$} \\
\hline & \multicolumn{2}{|c|}{ Multivitamin $^{b}$} \\
\hline Self-reported baseline characteristics & $\begin{array}{c}\text { Active } \\
(\mathbf{n}=7,317)\end{array}$ & $\begin{array}{c}\text { Placebo } \\
(n=7,324)\end{array}$ \\
\hline No & $6,988(95.5)$ & $7,992(95.5)$ \\
\hline Yes & $329(4.5)$ & $332(4.5)$ \\
\hline \multicolumn{3}{|l|}{ Self-reported history of colorectal cancer (No. $(\%))$} \\
\hline No & $7,255(99.2)$ & $7,264(99.2)$ \\
\hline Yes & $62(0.8)$ & $60(0.8)$ \\
\hline Fruit and vegetable intake (median $\left(25^{\text {th }}-\mathbf{7 5}^{\text {th }} \text { percentile), servings/d }\right)^{d}$ & $4.26(2.95-5.75)$ & $4.19(2.94-5.77)$ \\
\hline Whole grain intake (median $\left(25^{\text {th }}-\underline{75}^{\text {th }} \text { percentile), servings } / \mathbf{d}\right)^{d}$ & $1.13(0.49-2.00)$ & $1.07(0.49-1.99)$ \\
\hline Red meat intake (median $\left(25^{\text {th }}-{ }^{-75^{\text {th }}}\right.$ percentile), servings/d) ${ }^{d}$ & $0.63(0.29-1.05)$ & $0.57(0.29-1.00)$ \\
\hline
\end{tabular}

Abbreviations: SD, standard deviation

${ }^{a}$ Unless otherwise indicated. The numbers do not always sum to group totals due to missing information for some variables.

${ }^{b} \mathrm{P}>0.05$ for all comparisons between active and placebo multivitamin groups.

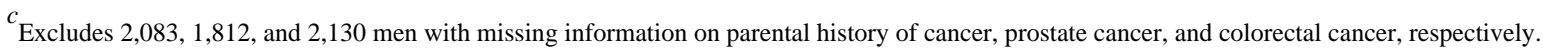

${ }^{d}$ Among 13,310, 13,280, and 13,268 men with available dietary data on fruit and vegetable, whole grain, and red meat intake, respectively. 


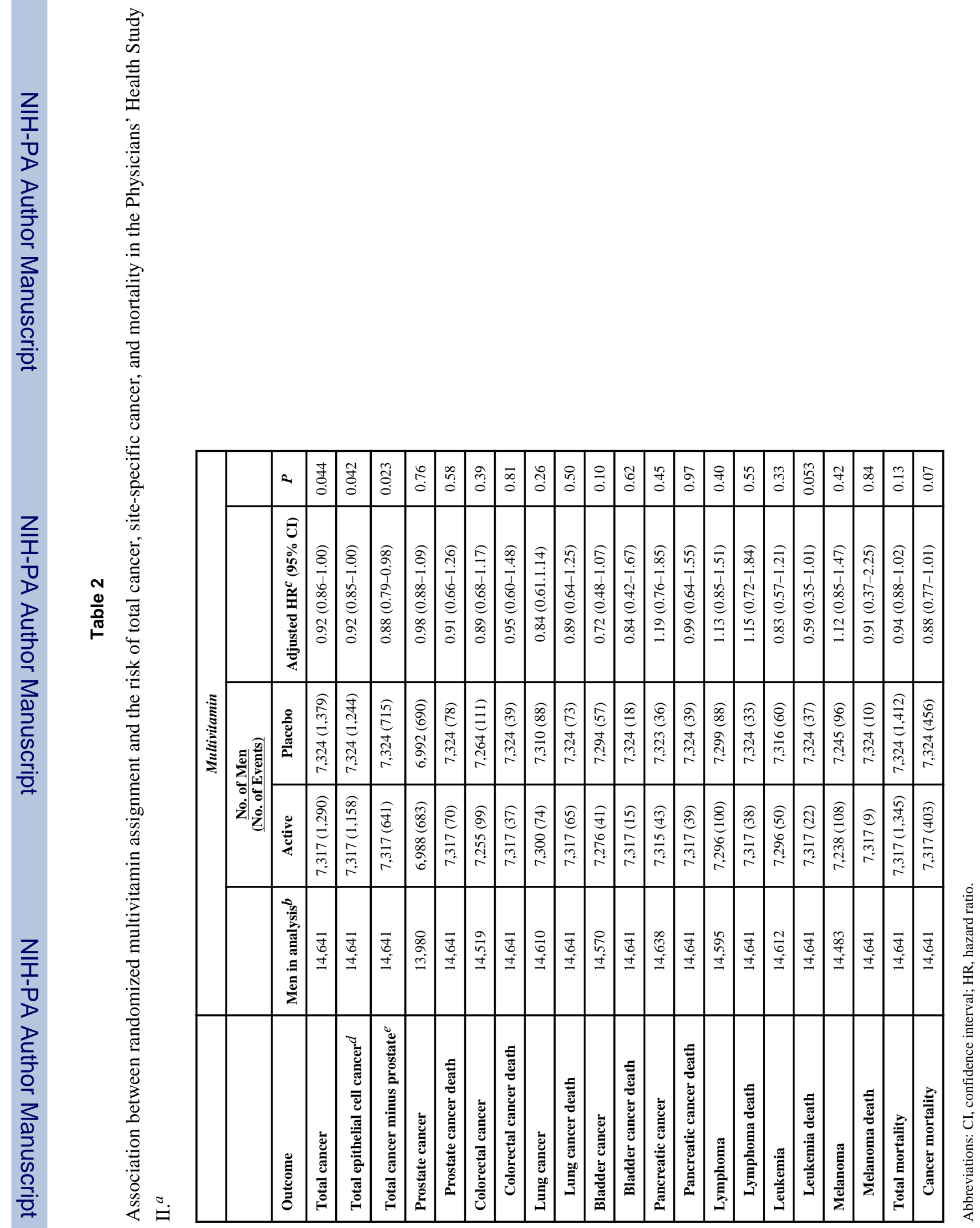




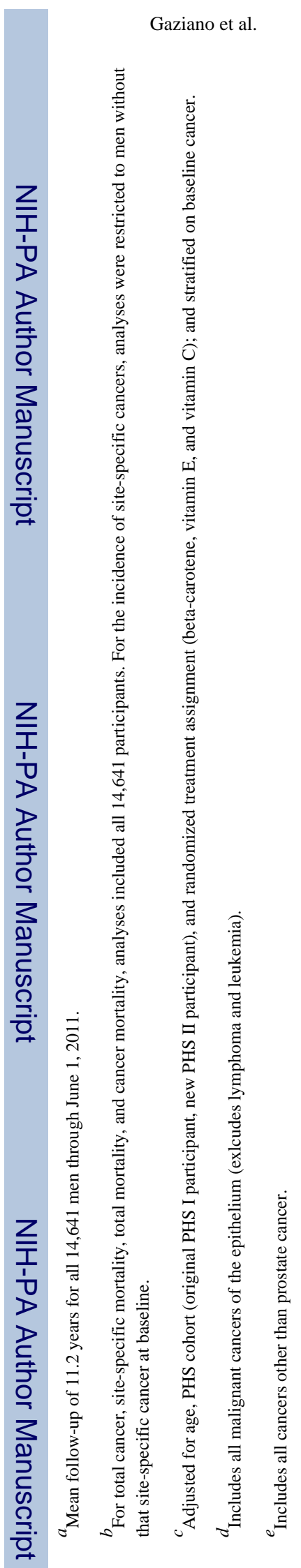

JAMA. Author manuscript; available in PMC 2013 November 14. 
浞

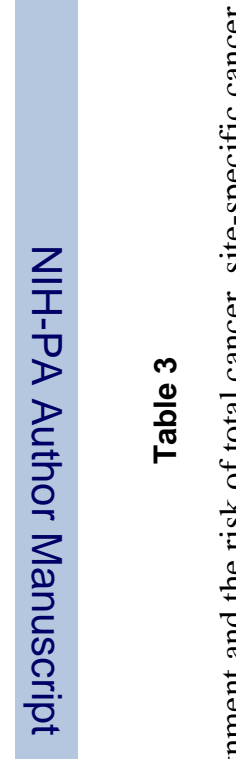

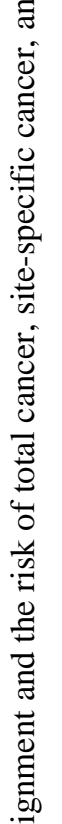

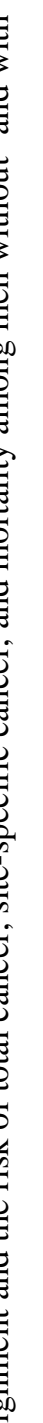

ב্

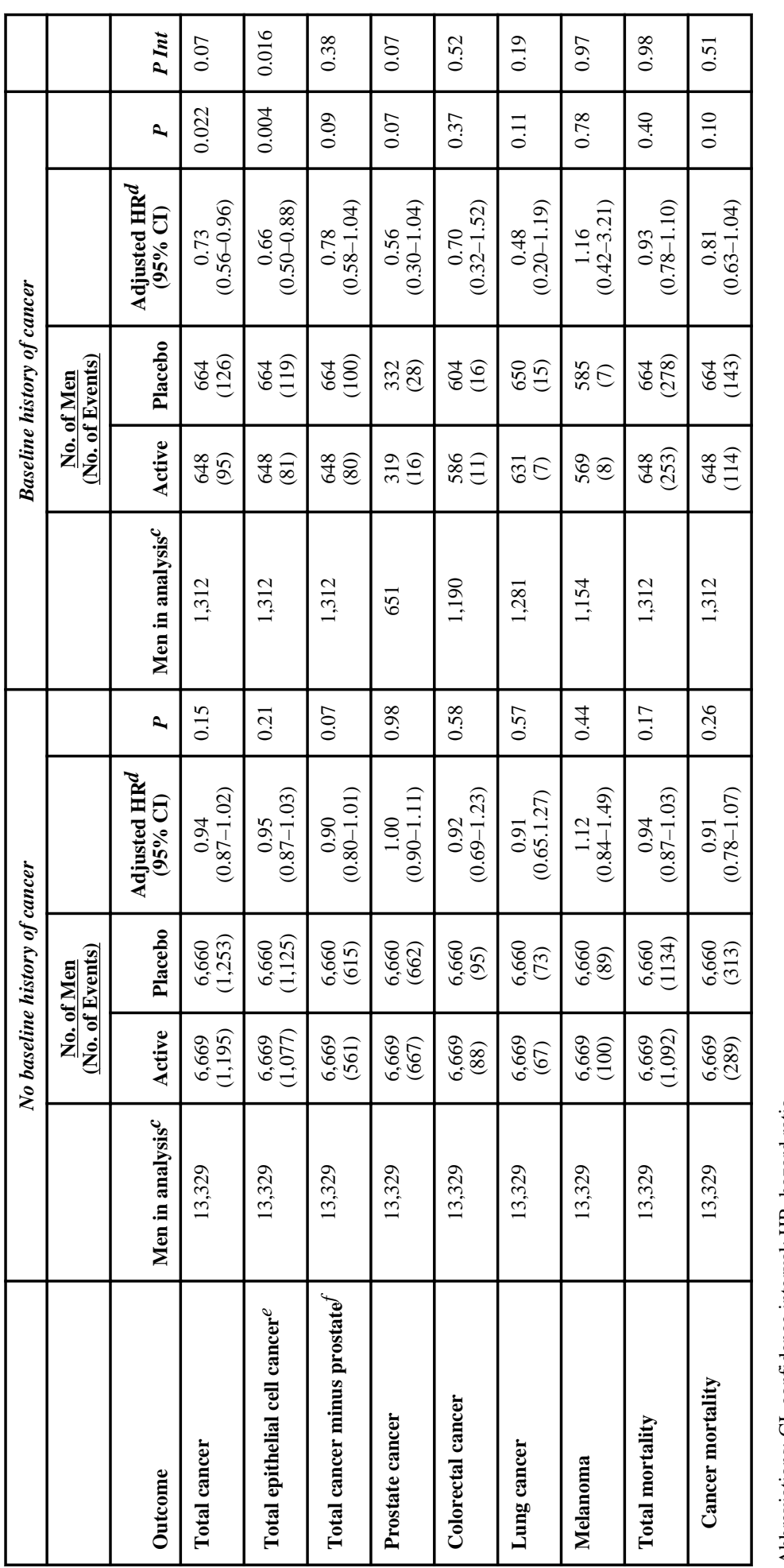

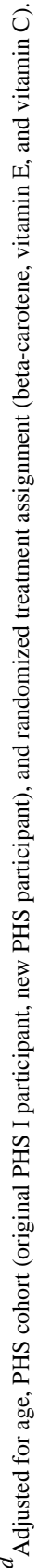

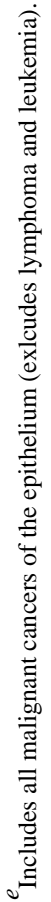


